\title{
Deflection-Based Aircraft Structural Loads Estimation With Comparison to Flight
}

\author{
Andrew M. Lizotte ${ }^{*}$ and William A. Lokos ${ }^{\dagger}$ \\ NASA Dryden Flight Research Center, Edwards, California, 93523-0273
}

\begin{abstract}
Traditional techniques in structural load measurement entail the correlation of a known load with strain-gage output from the individual components of a structure or machine. The use of strain gages has proved successful and is considered the standard approach for load measurement. However, remotely measuring aerodynamic loads using deflection measurement systems to determine aeroelastic deformation as a substitute to strain gages may yield lower testing costs while improving aircraft performance through reduced instrumentation weight. With a reliable strain and structural deformation measurement system this technique was examined. The objective of this study was to explore the utility of a deflection-based load estimation, using the active aeroelastic wing F/A-18 aircraft. Calibration data from ground tests performed on the aircraft were used to derive left wing-root and wing-fold bending-moment and torque load equations based on strain gages, however, for this study, point deflections were used to derive deflection-based load equations. Comparisons between the strain-gage and deflection-based methods are presented. Flight data from the phase-1 active aeroelastic wing flight program were used to validate the deflection-based load estimation method. Flight validation revealed a strong bending-moment correlation and slightly weaker torque correlation. Development of current techniques, and future studies are discussed.
\end{abstract}

\section{Nomenclature}

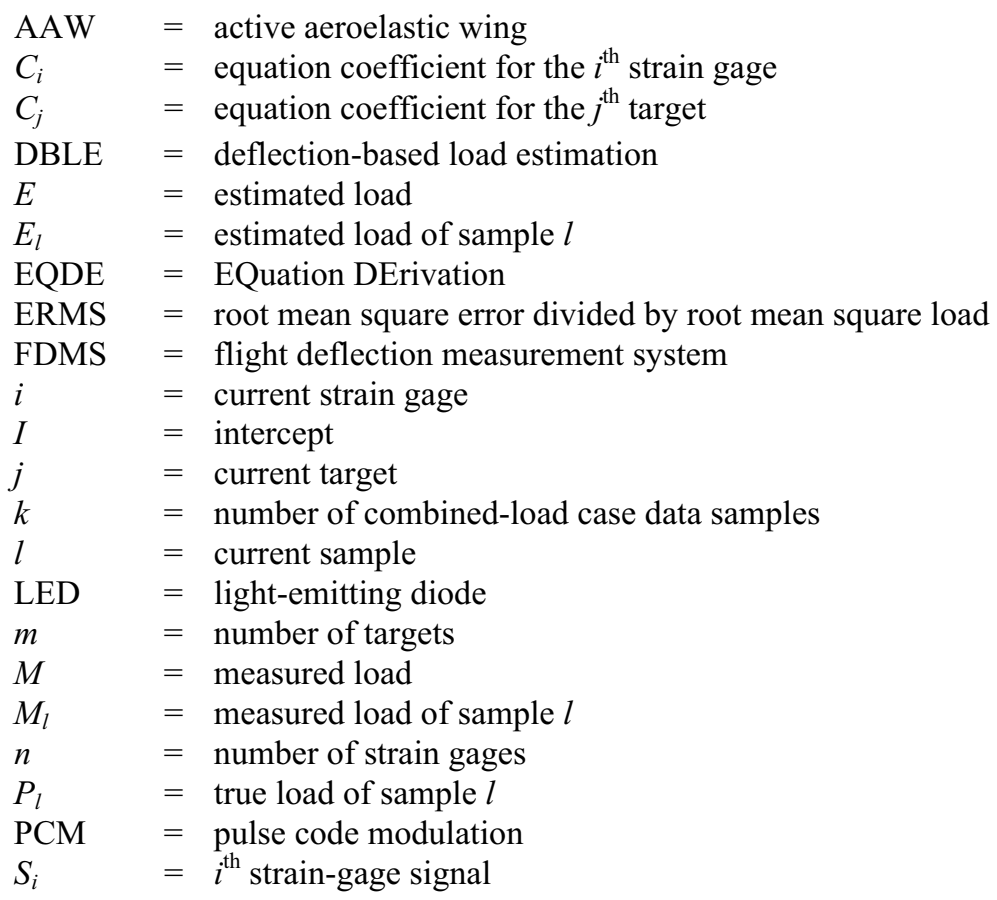

\footnotetext{
${ }^{*}$ Aerospace Engineer, Aerostructures, P.O. Box 273/MS 4820 2A.

${ }^{\dagger}$ Aerospace Engineer, Aerostructures, P.O. Box 273/MS 4820 2A.
} 


$\begin{array}{ll}T_{j} & =j^{\text {th }} \text { target signal } \\ \text { WFBL } & =\text { wing-fold bending moment } \\ \text { WFTL } & =\text { wing-fold torque } \\ \text { WRBL } & =\text { wing-root bending moment } \\ \text { WRTL } & =\text { wing-root torque }\end{array}$

\section{Introduction}

$\mathrm{T}_{\mathrm{n}}^{\mathrm{H}}$ HIS paper summarizes an effort to explore the feasibility of a deflection-based alternative to the traditional method of flight-load measurement. The traditional approach to flight-load measurement on aircraft structures uses metallic-resistance strain gages that are physically bonded directly to key elements of the structural load paths. The strain gages are wired into Wheatstone bridge circuits with onboard signal-conditioning units and excitation power supplies. Applied load causes each structural element to deform or strain, producing an electrical resistance change in the strain gage(s) proportional to the load. An aircraft strain-gage loads calibration is produced by the mechanical application of known loads during a ground-calibration test and recording the strain-gage output throughout the aircraft structure. Load equations for such things as wing bending moment and torque are derived post-test based on the strain measurements. ${ }^{1}$ In flight, the load equations produce calculated loads from the selected group of strain-gage millivolt outputs.

Just as there is an inherent relationship between the microscopic strains of key elements of a flight structure and the load that structure is carrying, there is also a relationship between the macroscopic deflection of the overall structure and the corresponding flight load. If, for example, the vertical deflections of a number of locations across a wing can be measured, these deflection measurements can be used, just as strain-gage output voltages are, in appropriately-derived load equations. The active aeroelastic wing (AAW) flight research project ${ }^{2}$ provided a unique opportunity to demonstrate the potential of this alternative approach to load measurement. During the AAW project, a broad combination of ground-test applied calibration loads, measured deflections, strain-gage data, and corresponding flight data were provided, allowing this research to be performed.

Even though strain gages are well-known commercial products supported by a wealth of industrial infrastructure, documented research, and often corporate knowledge and skill, they also have some drawbacks. For example, it is difficult to install strain gages on some materials, such as titanium. ${ }^{3}$ Likewise some aircraft strain-gage installations require a large amount of lead wire, consuming volume and adding weight to the vehicle; routing the lead wire from the signal-conditioning units to the strain gages can also be difficult. In addition, strain gages are subject to physical damage, thermal effects, fatigue, bond aging, cold solder joints, electromagnetic interference, and other difficulties.

The technique of deflection-based load estimation (DBLE) also has advantages and disadvantages as compared with strain-gage load measurement. In-flight deflection measurement is a much less mature field and currently has little commercial support. The DBLE technique may not yield good results on a relatively stiff structure, and flight environments can also pose difficulties for deflection measurement efforts. Optical deflection measurement systems may be subject to occasional blinding by direct sunlight and may also be hindered by flying through clouds. Finding a location for the optical receiver package sometimes complicates the deflection measurement installation design. However, it is thought that in some circumstances a DBLE method can be advantageous. For example, a relatively flexible aircraft with co-cured composite construction with redundant internal structure may be difficult to retrofit for strain-gage load measurement of some component loads but might lend itself to a successful DBLE effort. A DBLE methodology may produce a loads estimate with less weight impact than that of the integration of a traditional strain-gage network; this would be advantageous for a weight-critical aircraft. Likewise, it may be easier to retrofit an aircraft for in-flight wing deflection measurement than it would be to disassemble the wing to allow access to the internal structure if that is what is called for in the installation of strain gages, thus simplifying a ground-loads calibration. As in-flight deflection measurement techniques develop and become easier to apply, DBLE will become more advantageous.

\section{A. Similar Research and Techniques}

The process of using optical methods to measure load in ground studies has been performed at the NASA Langley Research Center (Hampton, Virginia). Liu, Barrows, Burner, and Rhew studied deformation of a tapered circular cross-section sting under normal static load. ${ }^{4}$ Local deformation quantities were measured using a videogrammetric system. Normal force and pitching moment were derived from the deformation results and compared to strain-gage outputs. The relative errors in the force and pitching moment obtained by the optical method were about \pm 5 percent as compared with \pm 2 percent given by the strain gages. Doyle, Liu, and Britcher investigated an optical technique for determining dynamic aerodynamic loads based on elastic deformation 
measurements of a beam using a videogrammetric system. Their model, which extracted the normal force and loading position from deformation data, allowed dynamic loads of low frequency to be calculated with reasonable accuracy. ${ }^{5}$

\section{B. Deflection-Based Load Estimation Method}

The purpose of the DBLE research effort was to determine the correlation between elastic wing deformation and applied load from AAW ground calibrations, evaluate the correlation using the AAW phase-1 flight data, and determine the validity of the DBLE method for future research and applications. In preparation for the AAW flight-test program an extensive strain-gage load calibration was performed. Applied loads, strain-gage responses, and elastic structural deflections were recorded. Linear regression analysis of the load and strain-gage data was used to produce strain-gage load equations for use in safety-of-flight monitoring of flight loads and post-flight loads research. The DBLE was made possible by the AAW ground- and flight-test database. The process of deriving load equations using strain-gage outputs was followed, but with the substitution of deflection data for the strain-gage data. This substitution produced deflection-based load equations derived from ground-test data that could be applied to flight-measured deflection data. The loads estimated by these equations were then compared to corresponding strain-gage-measured loads. Both wing bending-moment and torque comparisons were made from the ground calibration and from flight data.

\section{Active Aeroelastic Wing Load Calibration}

Figure 1 (EC04-0361-16) shows the AAW test bed, a highly-instrumented F/A-18 aircraft. Structural alterations to the airframe were made prior to the ground-load calibration test to achieve the AAW program objective of using wing twist to demonstrate roll control. The primary airframe structural alteration was the replacement of cover panels on the aft wing box with more flexible panels, thereby increasing the wing torsional flexibility. ${ }^{2}$

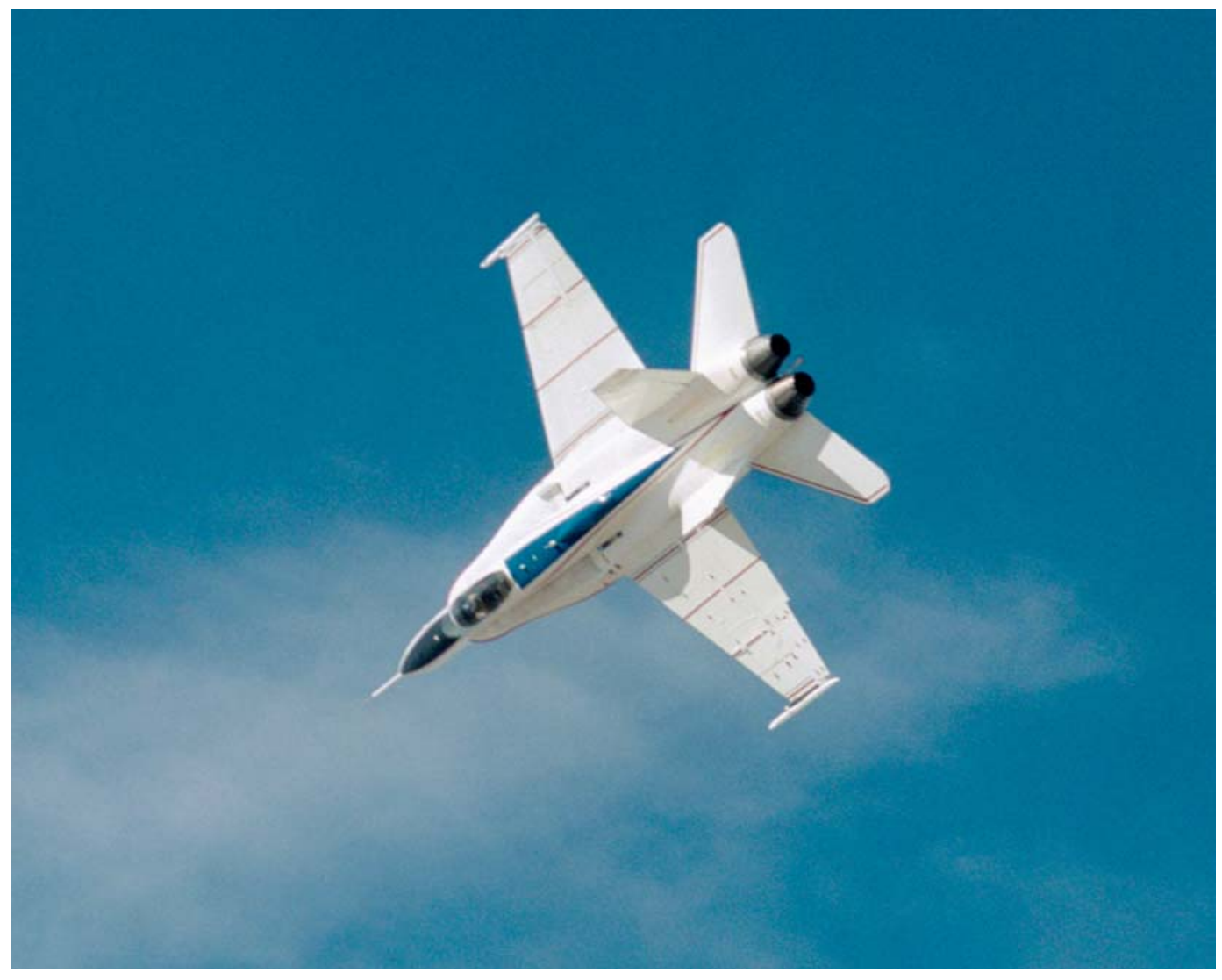

Figure 1. Active aeroelastic wing F/A-18 aircraft. 
Full utilization of wing strength was necessary to maximize roll performance. Based on this requirement, a great deal of attention was devoted to wing component instrumentation for safety-of-flight. Although standard on F/A-18 aircraft, the wing design was structurally complicated by seven inboard and six outboard spars and spanwise load-path interruption at the wing fold. Additionally, the design entailed a low aspect ratio and highly redundant load paths, making strain-gage load equation development a challenging task.

The AAW load calibration test was performed at the NASA Dryden Flight Research Center (Edwards, California) Flight Loads Laboratory ${ }^{6}$ in 2001 to ensure the development of accurate strain-gage-based load equations, and addressed applied-load testing design issues. Load calibration tests were conducted with approximately 60 percent of each lower wing surface covered with a total of 104 load pads. This method allowed both tensile and compressive loads to be applied at 16 load zones on each wing. A single load zone was comprised of a hydraulic jack, a load cell to measure the applied load, and a whiffletree mechanism to distribute the load to two, three, or four, load pads. Figure 2 is a photograph of the ground-calibration test setup on the left wing. Left and right wing loads were applied at the same respective locations so that the aircraft was symmetrically loaded. A total of 72 load cases including single-point-(one load zone per wing), double-point-(two load zones per wing), and distributed-(all 16 load zones per wing) load cases were applied. As a balance to ensure accurate wing-load monitoring and calibration research, a total of 158 strain-gage bridges were installed on the left and right wing boxes. $^{7}$ To monitor rigid-body motion during the load calibration, string potentiometers were placed at 16 points throughout the upper surface of the left wing. The ability to correctly monitor wing bending moment and torque ultimately depended upon adequate load testing and equation development. Because of the previously-mentioned structural modifications, vast amount of instrumentation and load calibration data, the AAW was an ideal test bed for DBLE development.

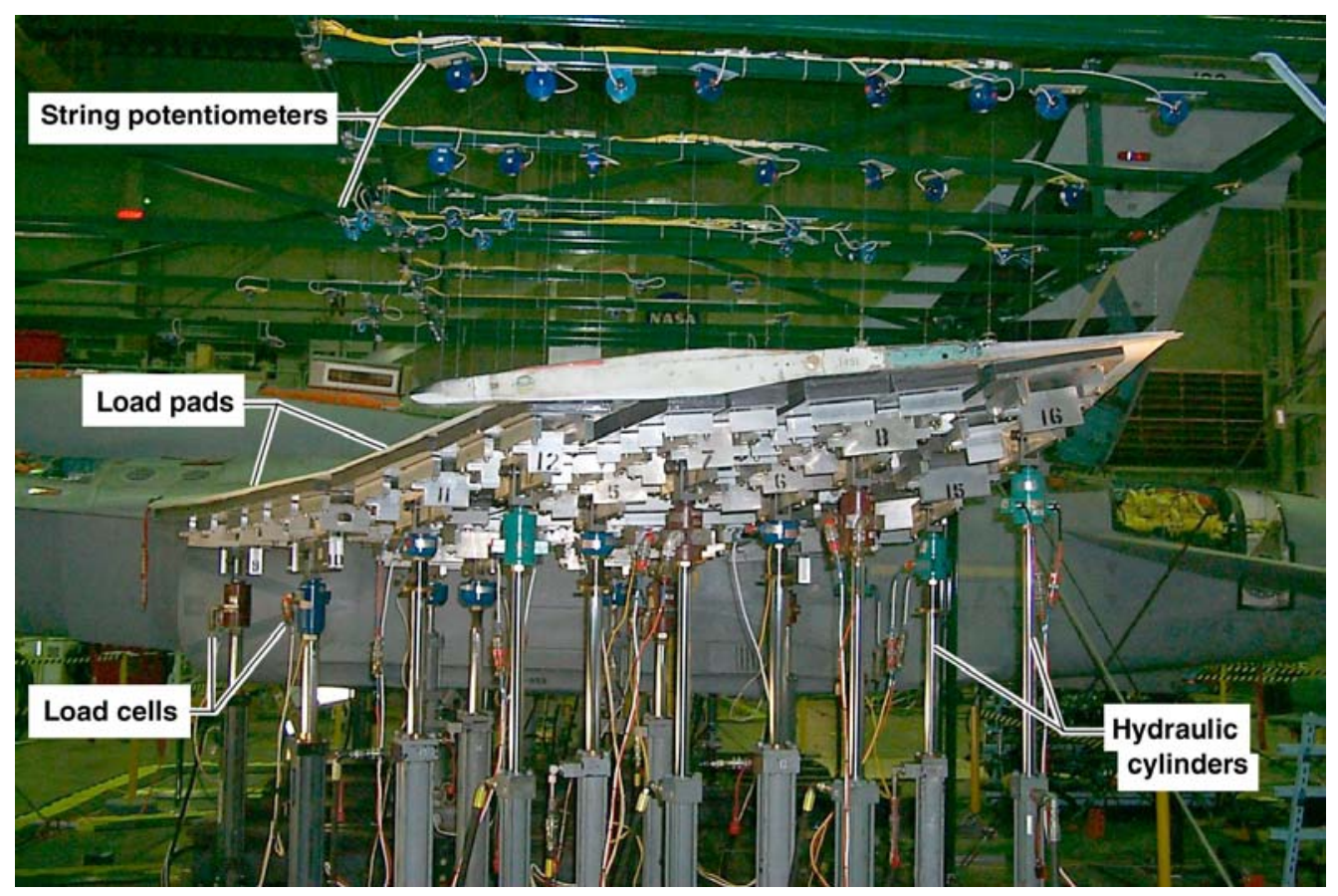

Figure 2. Active aeroelastic wing left-wing instrumentation and hardware during load calibration.

\section{A. Active Aeroelastic Wing Strain-Gage Load Equation Development}

For this analysis the general term "loads" refers to the wing-root bending moment (WRBL), wing-root torque (WRTL), wing-fold bending moment (WFBL), and wing-fold torque (WFTL), of the left wing, as shown in Fig. 3. 


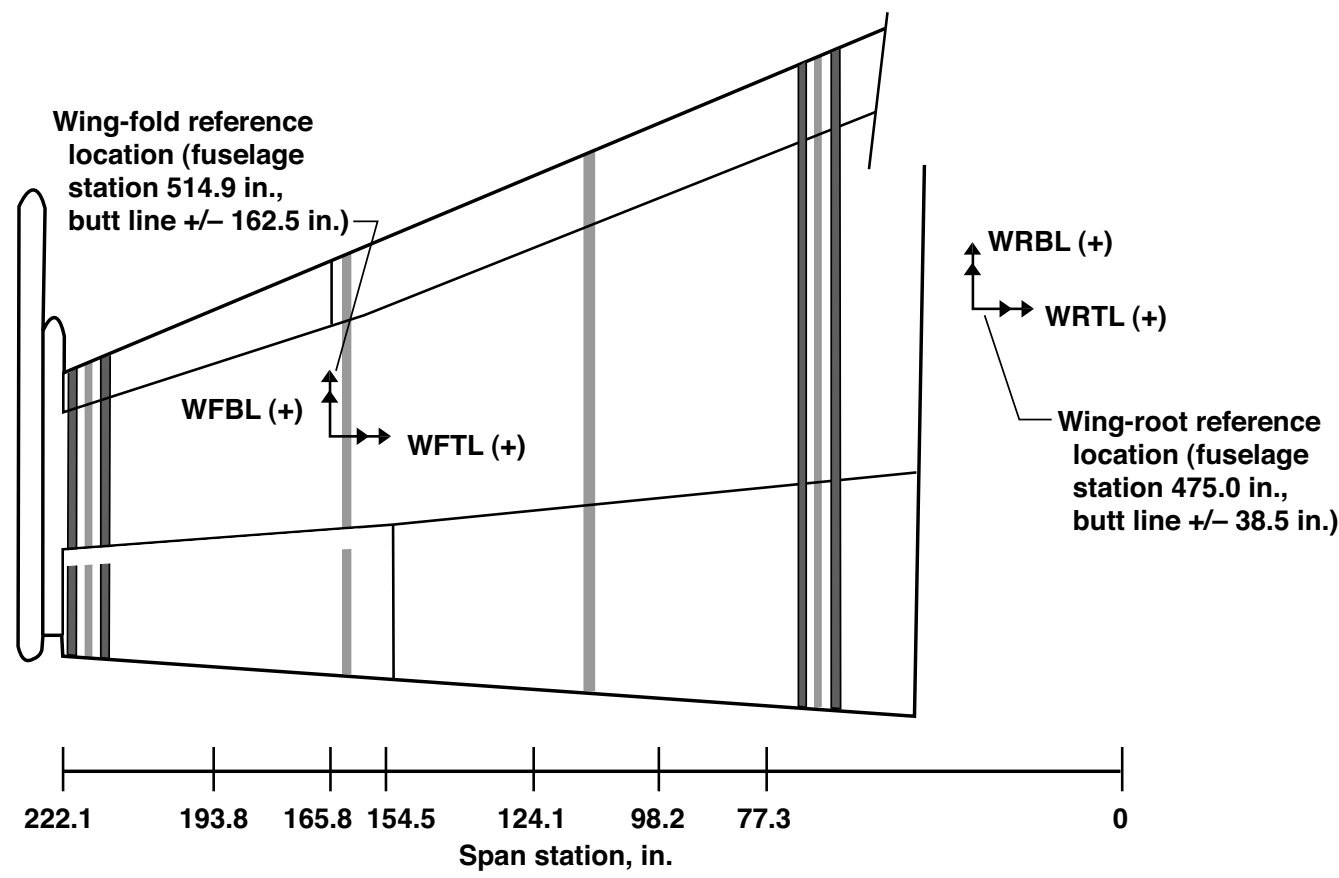

Figure 3. Left wing-root and wing-fold reference locations.

Equations to measure loads were created by using an in-house multiple linear regression tool called equation derivation (EQDE). The linear regression approach to develop mathematical load equations from strain-gage responses is the most commonly-used method today. ${ }^{8}$ Traditionally, EQDE has been used to facilitate the process of deriving load equations from large quantities of strain-gage data collected from loads calibration tests. The primary function of EQDE is to derive equation coefficients from a given set of independent variables (strain gages) and a single dependent variable (load). The equation coefficients were then used to calculate the measured model load $M$,

$$
M=I+\sum_{i=1}^{n} S_{i} C_{i}
$$

where $n$ is the number of strain gages, $C_{i}$ is the equation coefficient for the $i^{\text {th }}$ strain gage, $I$ is the intercept and $S_{i}$ is the $i^{\text {th }}$ strain-gage signal. Equation (1) above calculates a single load at a single point in time, making the load equation time-invariant. Typically three to five strain gages, out of a much broader pool, are selected based on their high correlation with the applied load.

Two approaches to run EQDE were used to achieve the optimal set of strain gages and corresponding equation coefficients. The first approach was to explicitly specify which strain gages to use in each equation; the second approach was to allow EQDE to perform an exhaustive search. The exhaustive search analyzed all possible straingage combinations to produce an equation with a consistent load relationship relative to a specified set of strain-gage inputs. Both approaches were used in analysis of AAW calibration data to determine the lowest load-equation error. Equation (2) shows the metric used to quantify load equation results and to rank exhaustive search results; root mean square error divided by root mean square load (ERMS).

$$
\mathrm{ERMS}=\left[\frac{\sum_{l=1}^{k}\left(M_{l}-P_{l}\right)^{2}}{\sum_{l=1}^{k} P_{l}^{2}}\right]^{\frac{1}{2}}
$$


where $k$ is the number of combined-load case data samples, $M_{l}$ is the measured load of sample $l$ and $P_{l}$ is the true load, as measured by the load cell, of sample $l$. The ERMS error is one of the most commonly-used statistical measures of equation fit. Lower ERMS error indicates a closer match between the measured load and the true load. The AAW strain-gage calibration ERMS error for the primary wing-root bending and torque and primary wing-fold bending and torque are shown in table 1. Figure 4 outlines the strain-gage load equation development process flow.

Table 1. Strain-gage load calibration error.

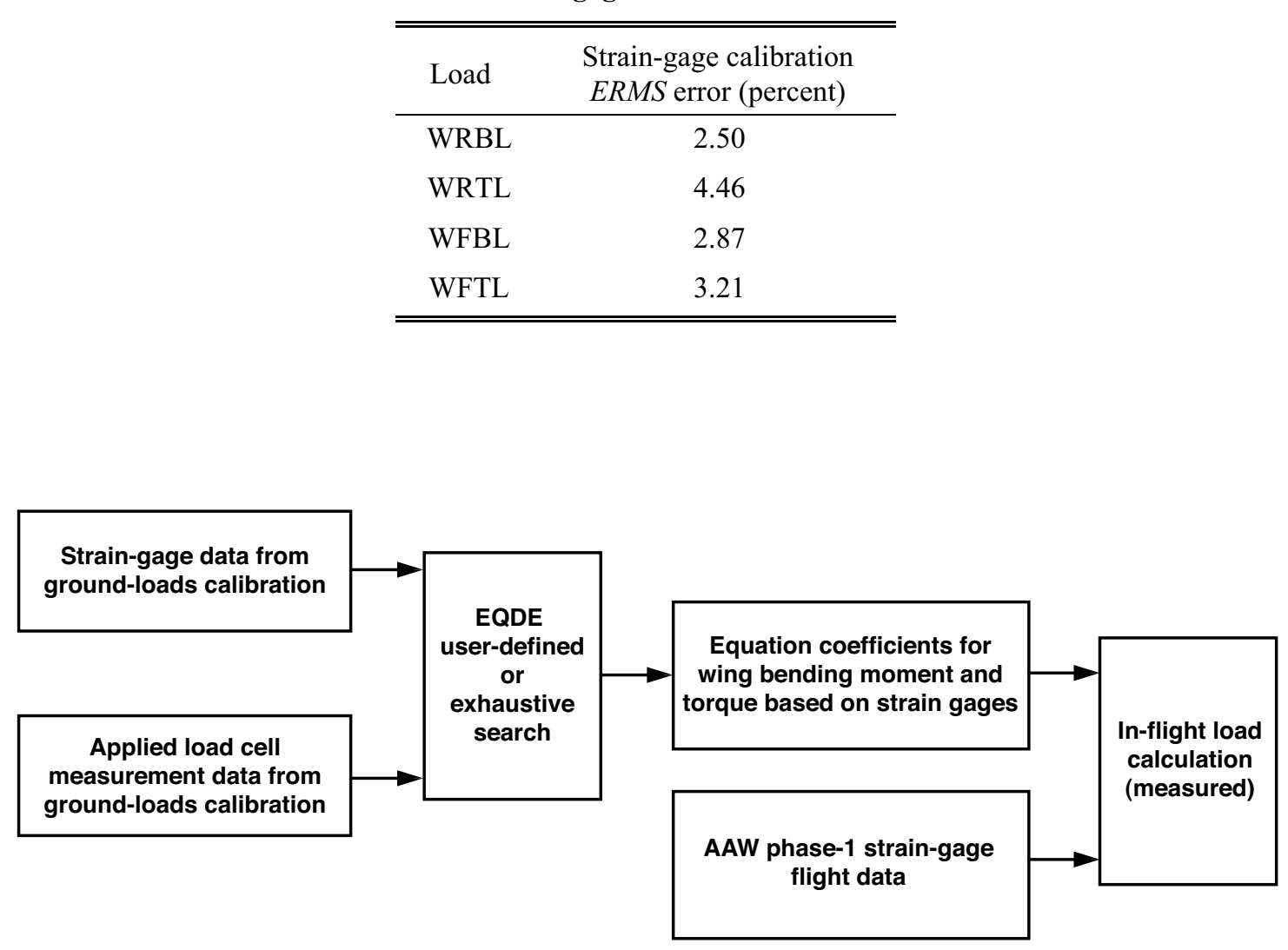

Figure 4. Strain-gage load equation development process flow chart.

Although all three forms of loading cases were used to develop strain-gage load equations, the general trend was for the equations derived from the distributed-loading test data to be better than those derived from the single-point and double-point loading test data. ${ }^{9}$ The distributed-load cases utilized all 16 load zones simultaneously, allowing a much higher total net load than the single-point cases. Distributed applied loads reached 70 percent of the flight-load limit whereas the single-point loading cases reached a fraction of the flight-load limit.

\section{B. Active Aeroelastic Wing Deflection Measurements}

As previously mentioned, string potentiometers were used during the ground-load calibration to measure displacement at 16 points on the left wing. Since this method was not available during flight, another method was used to record the wing deformation during flight. Burner, Lokos and Barrows have shown that in flight, single-view photogrammetric methods have proven useful for aeroelastic deformation measurements for the AAW F/A-18 aircraft, ${ }^{10}$ however, the DBLE study utilizes an alternate technique called the flight deflection measurement system (FDMS), ${ }^{11}$ to measure in-flight wing deflection. 
Sixteen infrared light-emitting diodes (LEDs), were installed on the upper surface of the AAW wing, shown in Fig. 5, to continuously measure the aeroelastically-deformed shape of the left wing. Collocated with the string potentiometer placements during the ground calibration, the FDMS targets were scanned sequentially beginning with target 0 and ending with target 15 . Sequencing through the 16 LED targets took $80 \mathrm{~ms}$, at which time the sequence began again with target 0 , thus producing a sampling rate of 12.5 samples per second for each target. This sampling rate was adequate for quasi-static structural measurements, even for high-rate maneuvers such as abrupt step commands to the control surfaces. Specific maneuvers flown by the AAW lasted from $4 \mathrm{~s}$ for a 100-percent lateral stick maneuver to approximately $33 \mathrm{~s}$ for a doublet maneuver.

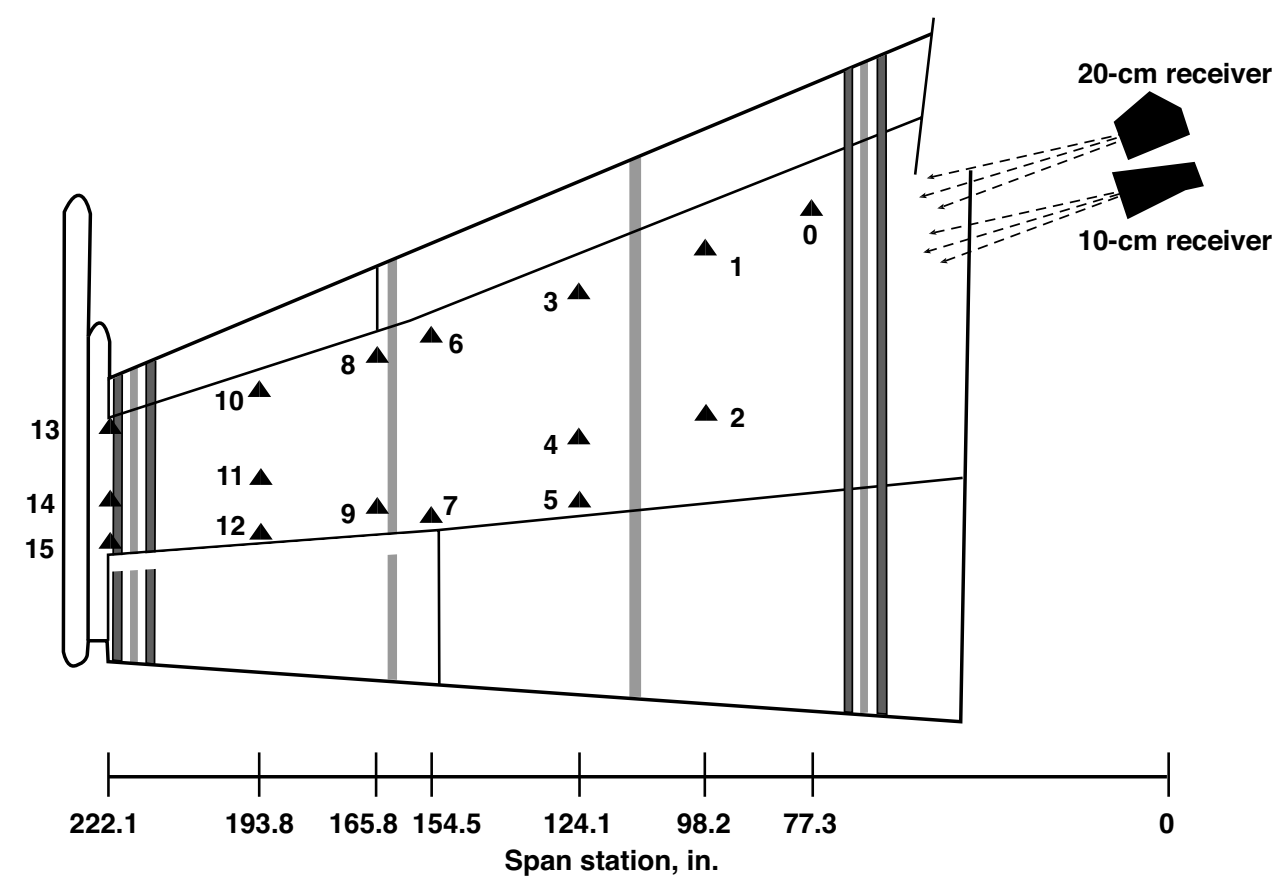

Figure 5. String potentiometer and flight deflection measurement system target placement illustration.

Light from the target LED is focused as a horizontal line on a light-sensitive diode array mounted at the lens focal point. The receiver sends an electrical signal proportional to the point at which the target light encounters the diode array to the FDMS control unit. Figure 6 shows an overhead photograph of the two optical receivers, which were mounted in the pod just aft of the cockpit to receive target data. A $10-\mathrm{cm}$ focal length receiver was used to view inboard targets 0 through 9 , while a 20 -cm focal length receiver viewed the outboard targets, 10 through 15 . Combining the two receivers provided a balance between complete field of view and acceptable resolution. The control unit, which contains the logic necessary to operate the FDMS, also served to interface the FDMS with the pulse code modulation (PCM) data-recording system onboard the AAW aircraft. The deflection data were recorded as two 10-bit digital words. One word contained position data while the other contained the target identification and error messages. Once acquired by the PCM system, the data were transmitted to a ground station for recording. Previous applications of the FDMS technology include the Highly Maneuverable Aircraft Technology, ${ }^{12}$ the X-29 forward-swept-wing aircraft, ${ }^{13}$ the Advanced Fighter Technology Integration F-111 Mission Adaptive Wing research aircraft, ${ }^{14,15}$ and the F-16C Block 40 aircraft. ${ }^{16}$ 

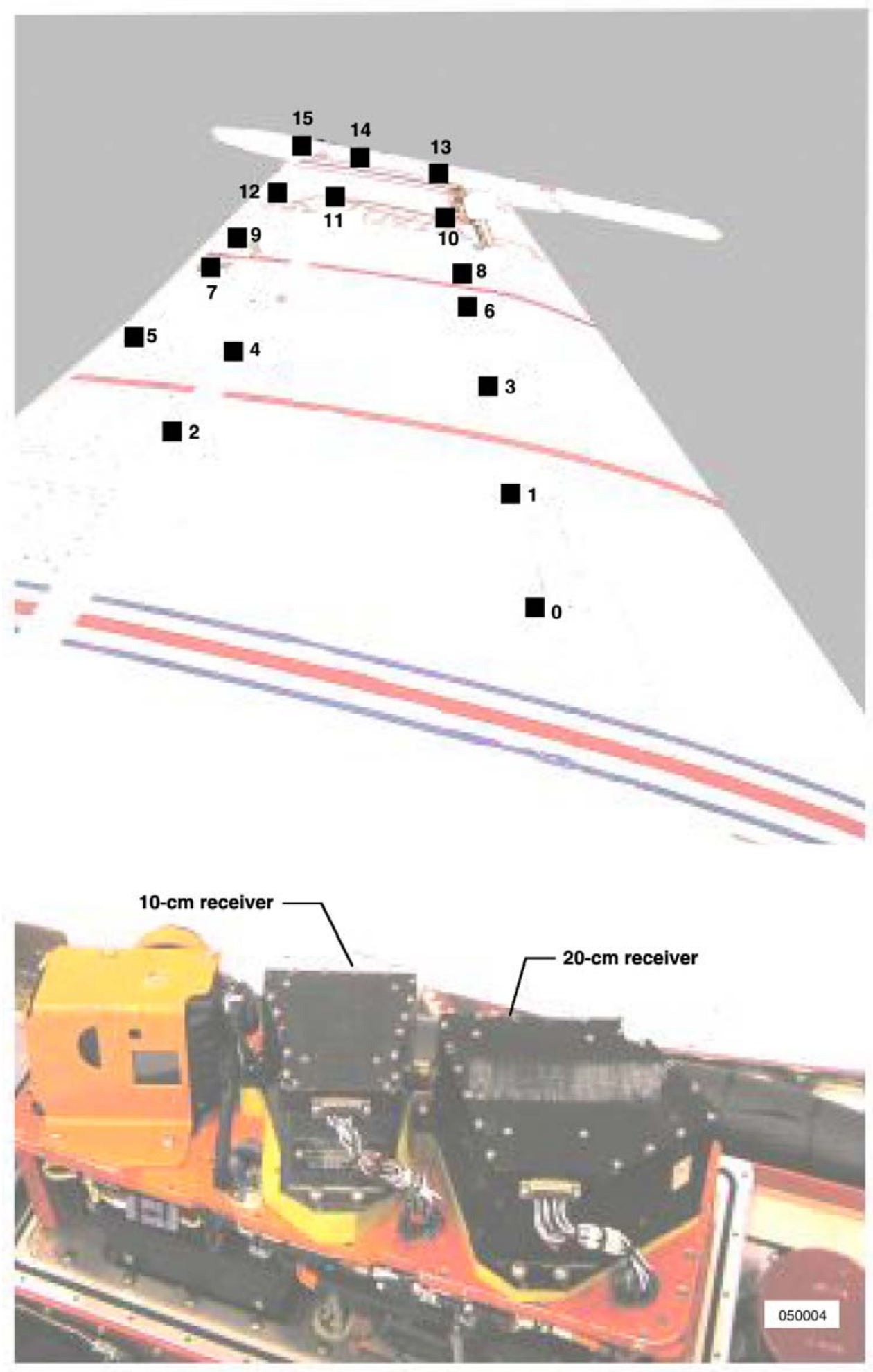

Figure 6. String potentiometer and flight deflection measurement system target placement photograph. 


\section{Instrumentation Accuracy for Deflection Measurements}

With any measurement device, the precision of the measurement is an important consideration. Figure 7 shows worst-case resolution for the FDMS and string potentiometer instrumentation. ${ }^{17}$ Similar to the X-29 FDMS setup, the vertical field of view for each FDMS target was resolved into 1024 data counts. The broadest possible error band of a single measurement is \pm 2 counts. Calibration error may be reduced to approximately \pm 0.25 counts over the calibration range, making this error negligible on total measurement system accuracy. Trending the deflection data over an interval of time allows the effective measurement error to approach that from the calibration error, yielding results much better than this worst-case plot.

Because of the use of two receivers with differing focal lengths, the corresponding pairing of targets to the receivers made the FDMS deflection resolution at span station 193.8, in Fig. 7, better than any other span. Figure 7 shows the worst-case resolution from the FDMS and a conservative estimate of string potentiometer resolution.

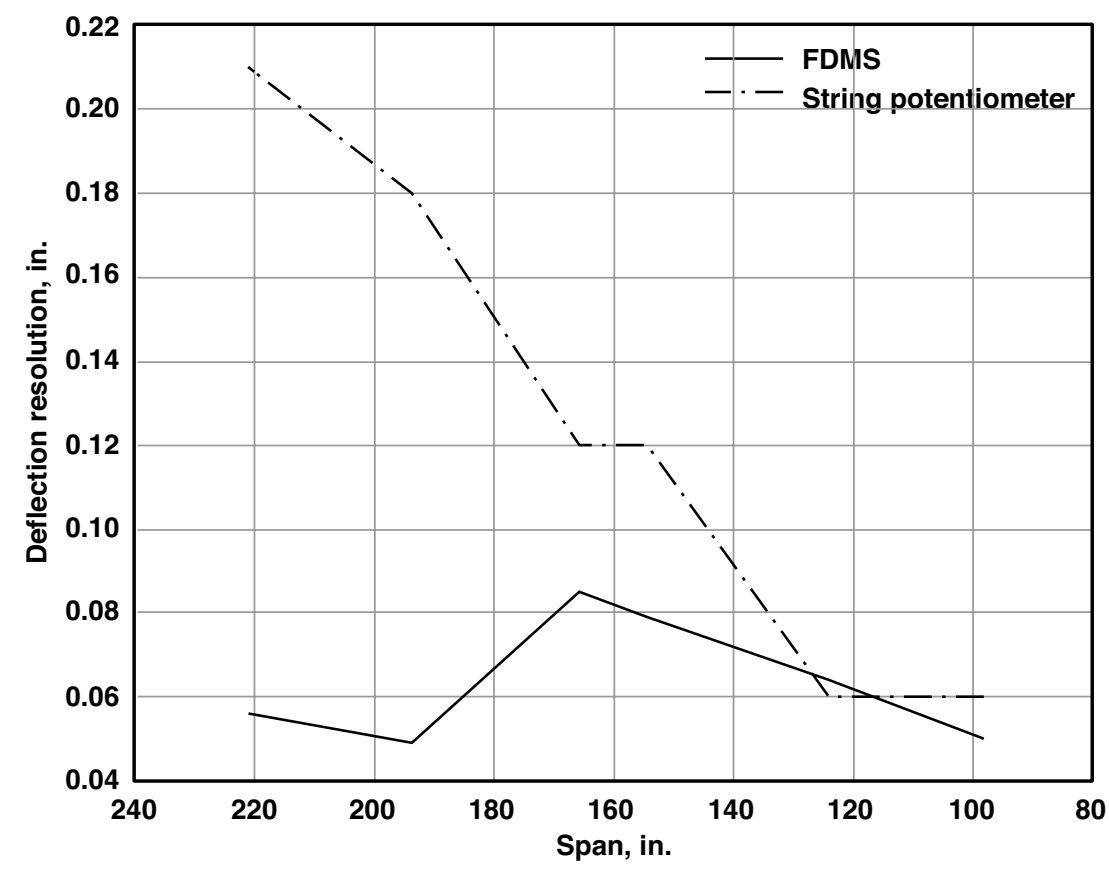

Figure 7. Flight deflection measurement system and string potentiometer resolution.

\section{Deflection-Based Load Estimation Equation Development}

Based on obtaining better strain-gage error results from the distributed-load cases and to simulate flight more accurately, the deflection-based load equation development strictly utilized distributed-loading case data. In the DBLE case, EQDE was used to develop load equations from string potentiometer deflection outputs instead of strain-gage outputs. Although string potentiometers were used during the ground-load calibration tests because of their availability and compatibility with laboratory data acquisition, the FDMS recorded deflection data during phase-1 flight. Figure 8 outlines the deflection-based load equation development process flow. Equations (3) and (4) are the load and error calculations for the estimated load, $E$,

$$
E=I+\sum_{j=1}^{m} T_{j} C_{j}
$$

where $m$ is the number of FDMS targets used, $C_{j}$ is the equation coefficient for the $j^{\text {th }}$ target, $I$ is the intercept, and $T_{j}$ is the $j^{\text {th }}$ target signal. As with Eq. (1), Eq. (3) calculates a single load at a single point in time, making the load equation time-invariant. The same metric was used to quantify load equation results and rank exhaustive search results: 


$$
\text { ERMS }=\left[\frac{\sum_{i=l}^{k}\left(E_{l}-P_{l}\right)^{2}}{\sum_{i=l}^{k} P_{l}^{2}}\right]^{\frac{1}{2}}
$$

where $k$ is the number of combined-load case data samples, $E_{l}$ is the estimated load of sample number $l$ and $P_{l}$ is the true load of sample $l$. Strain-gage calibration and DBLE results are hereinafter referred to as "measured" and "estimated" results, respectively.

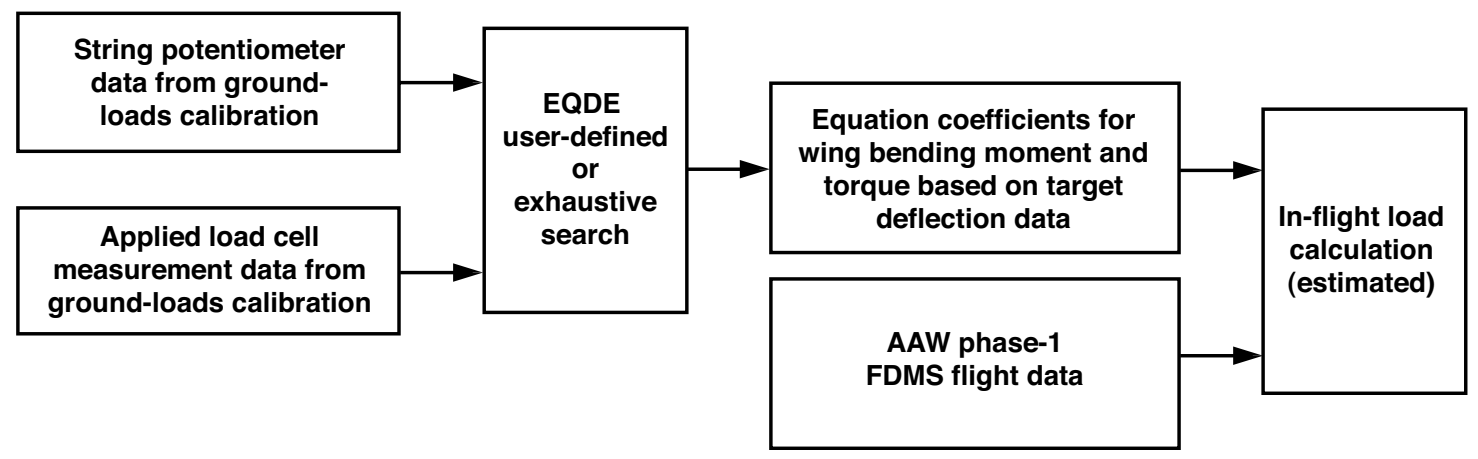

Figure 8. Deflection-based load equation development process flow chart.

As with strain-gage based load equations, the development of more accurate load estimates from deflection-based load equations results from a greater number of independent variables (target deflections). Four different target deflections along the wing span were sufficient to achieve low error for root and fold bendingmoment loads, while five target deflections were employed to define the root and fold torque loads. The ERMS error from the DBLE calibration for the wing-fold bending and torque and wing-root bending and torque are shown in table 2. Also shown in table 2 are the targets used to calculate each respective load.

Table 2. Deflection-based load estimation error and targets used for load calculation.

\begin{tabular}{ccc}
\hline \hline Load & $\begin{array}{c}\text { DBLE calibration } \\
\text { ERMS error (percent) }\end{array}$ & $\begin{array}{c}\text { Targets } \\
\text { (see figures 5 and 6) }\end{array}$ \\
\hline WRBL & 1.88 & $4,6,12,13$ \\
WRTL & 5.77 & $3,4,11,12,14$ \\
WFBL & 7.62 & $11,12,13,15$ \\
WFTL & 6.52 & $10,11,12,13,14$ \\
\hline \hline
\end{tabular}

As suggested by the ground calibration, estimated root bending-moment loads were much more accurate than the other three estimated loads. The strain-gage approach also shows the measured root bending-moment load to be more accurate than the other three loads as displayed in table 1 . Table 1 also shows the fold bending moment to be extremely accurate, however, the estimated fold bending moment had the highest error at 7.62 percent. The measured torque errors from table 1 are slightly better than the estimated torque errors from table 2 . In some structural configurations, strain-gage-based torque errors tend to be higher than those for bending because of the lower strains involved and the effect of structural redundancy. In summary, AAW ground-calibration results indicate that DBLE is a more accurate method than the strain-gage method to calculate root bending-moment loads, while DBLE is less accurate in calculation of fold bending-moment and torque loads. 


\section{Flight Validation}

Estimated loads (based on deflection) were calculated and compared to measured loads (based on strain) from AAW phase-1 flight data during various maneuvers. Maneuvers compared at various flight conditions were rolls at several lateral stick inputs, 5- $g$ wind-up turns, and doublets. In addition to loads comparisons, other issues which influenced the results were investigated including structural hysteresis, wing-fold mechanical free-play, and resolution.

\section{A. Flight Data Comparison}

According to the ground-calibration results found in table 2, the wing-root bending moment produced the least estimated error. As a percentage of structural limit, Fig. 9 shows estimated and measured bending-moment time histories for a typical 5-g wind-up turn. The measured and estimated load traces are shown by a solid and a dashed line, respectively. Grid spacing from the positive and negative loads may appear different in some cases because of dissimilar positive and negative structural load limits.

Figure 9(a) shows the AAW wing-root bending moment and Fig. 9(b) shows the AAW wing-fold bending moment. As expected from the ground-calibration error analysis, the estimated and measured WRBLs in Fig. 9(a) display a highly correlated relationship. Beginning at time $=0 \mathrm{~s}$, approximately $28.5 \mathrm{~s}$ of data is shown where the loads reach about 55 percent of the structural limit. Despite the high WFBL error from table 2, the component load yielded a close comparison to the strain-gage method as shown in Fig. 9(b). These trends were consistent throughout the analyzed flight maneuvers. Figures 10(a) and 10(b) show the WRBLs and WFBLs for a 100-percent lateral stick roll. The trend of a slightly better-predicted WRBL than WFBL was consistent.

As indicated by table 2 and Figs. 9(a) through 10(b), the wing-root and wing-fold torque loads would be slightly worse than the bending-moment loads. Figures 11(a) and 11(b) show the wing-fold torque loads for the same wind-up turn and roll illustrated in Figs. 9(a) through 10(b). Again the estimated and measured load traces are shown by solid and dashed lines, respectively. Only wing-fold torque loads are displayed, as the tendency was for the wing-root torque loads to be similar to the wing-fold torque loads. This tendency was that of slightly less correlated measured and estimated torque loads when compared to the previously-mentioned bending moment loads. Likely reasons for this discrepancy are structural hysteresis, wing-fold mechanical free-play, and resolution.

\section{B. Structural and Resolution Considerations}

Residual wing state from previous loading biases the structural response during a maneuver of interest. This effect is caused by the interaction between wing structural components including spar-to-wing-panel-rib friction and fastener fits that are worn beyond production tolerance, or generally loose fits. For the AAW aircraft, significant effort was devoted to improving the fastener fit for the upper and lower aft wing-box cover panels and some main wing-box fasteners. Although it was reported that structural hysteresis in the modified wing was reduced, ${ }^{18}$ the behavior was still present.

Figure 11(b) shows a full lateral stick roll, measured and estimated wing-fold torque time history. As assumed with structural hysteresis, a lag occurs between load estimation and measurement. Figure 11(b) shows the estimated load leading the measured load in this roll. At an approximate WFTL of 25 percent, wing vertical movement is recorded prior to load response. The estimated load stabilizes and continues to lead the measured load through the zero-torque transition. Again the estimated load exceeds the measured load prior to the return of steady and level flight. Note that the percent of torque structural limit reaches approximately -200 when the measured load only touches -75 . 


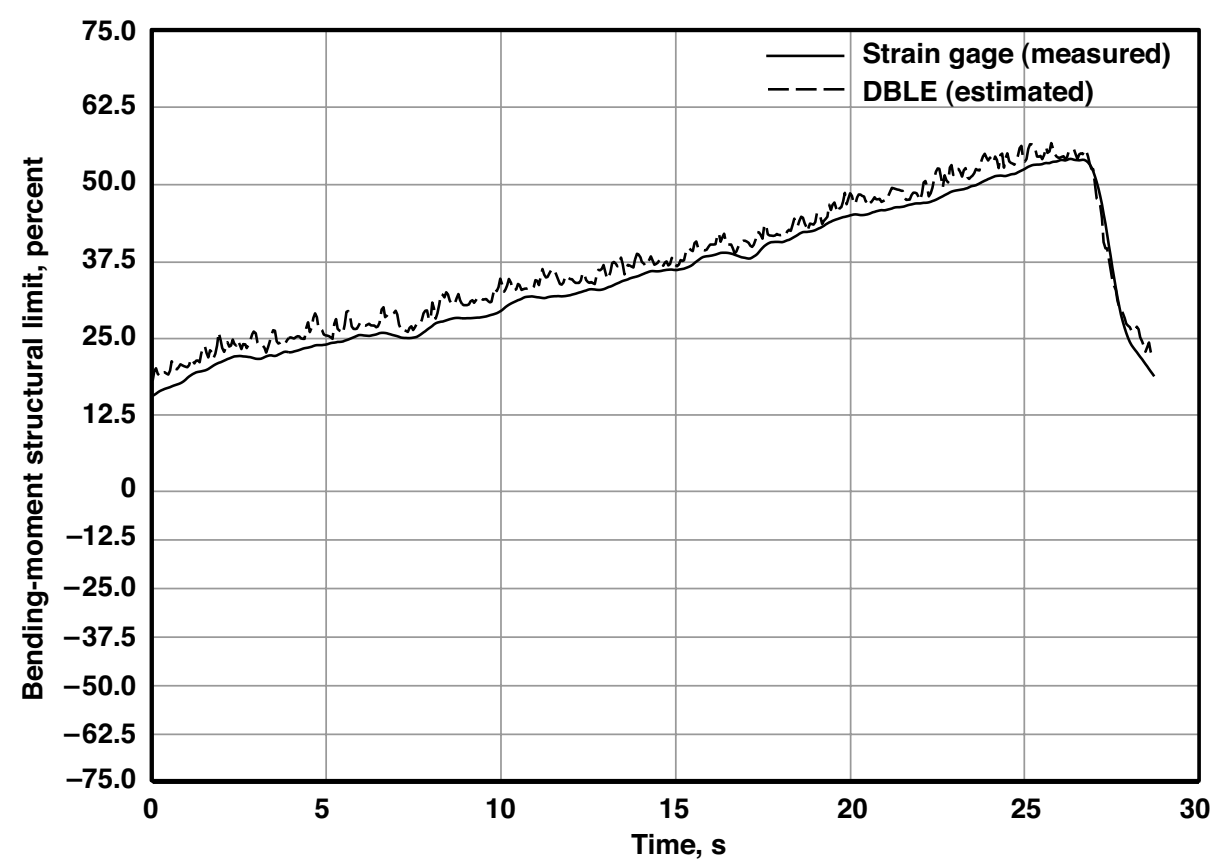

a) Wing-root bending moment.

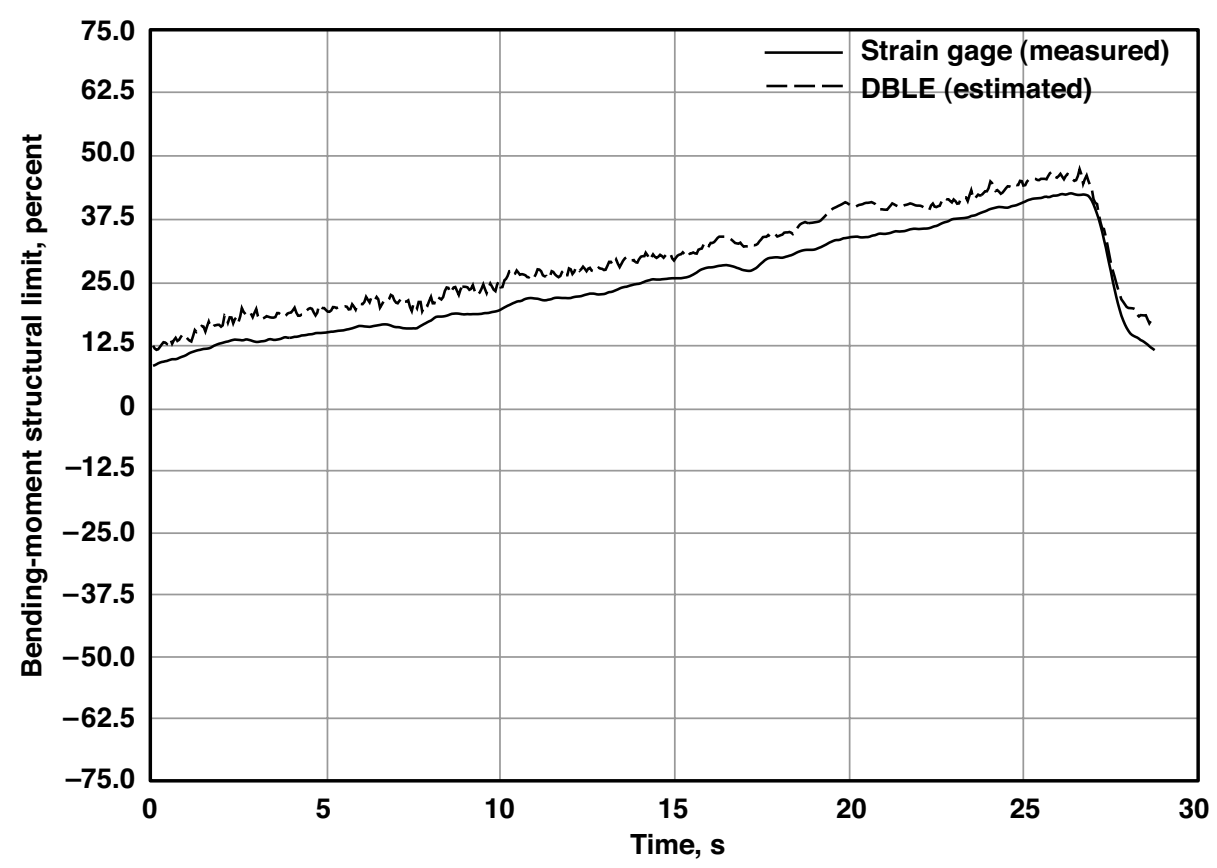

b) Wing-fold bending moment.

Figure 9. 5-g wind-up turn bending-moment time history plots. 


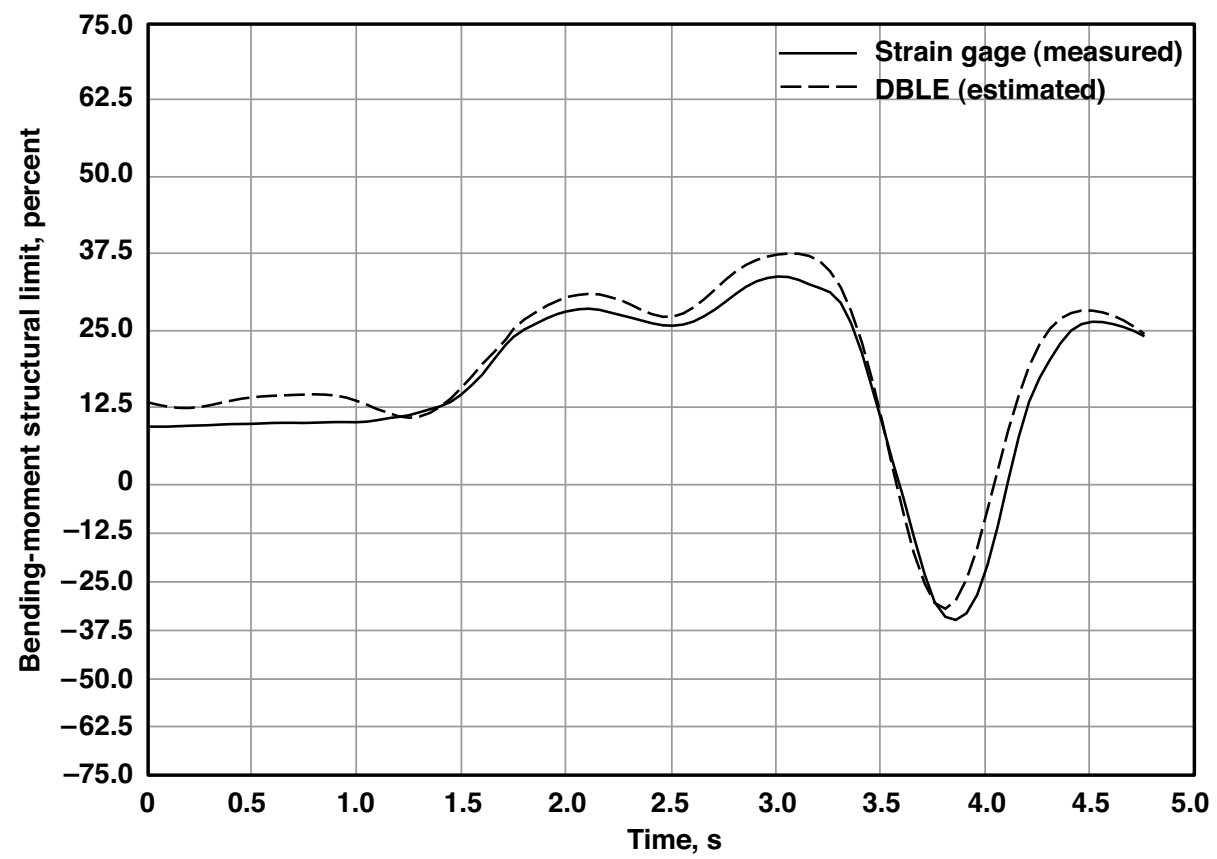

a) Wing-root bending moment.

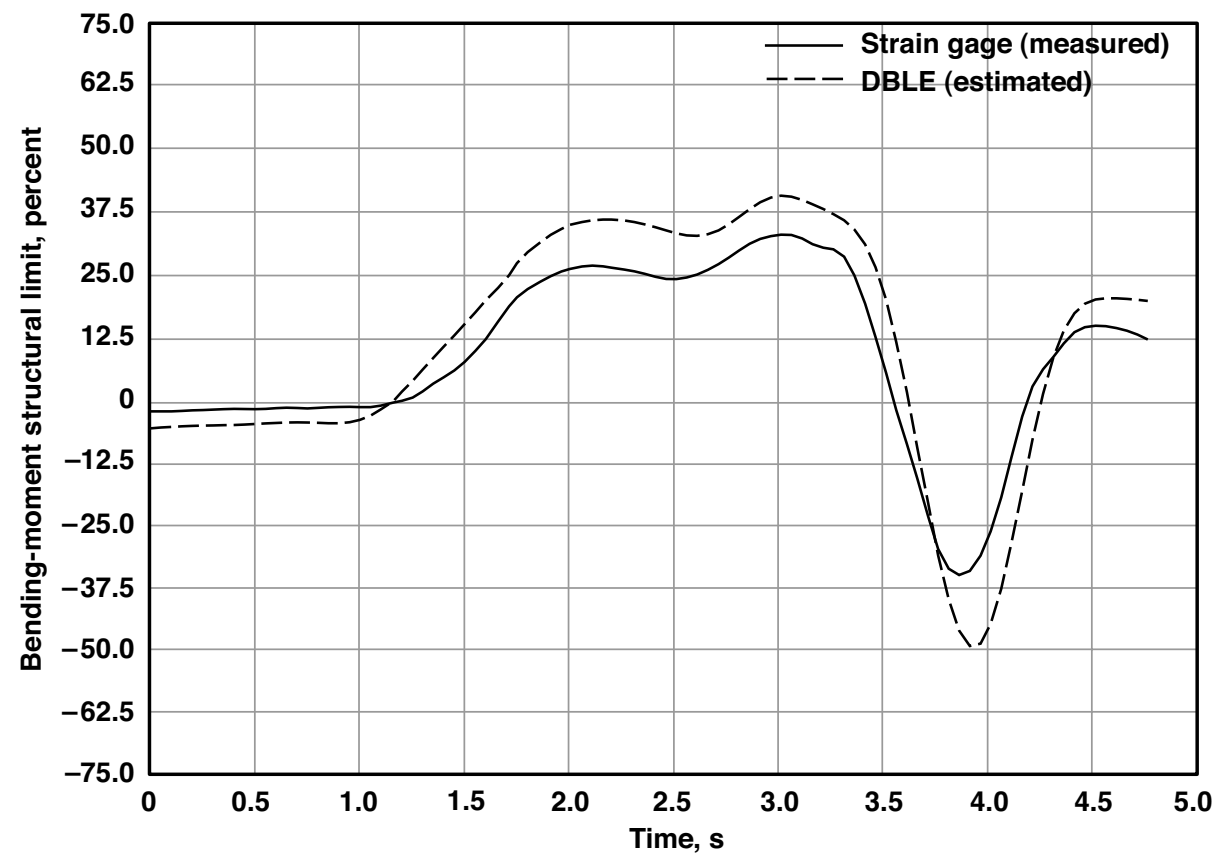

b) Wing-fold bending moment.

Figure 10. One-hundred-percent lateral stick roll bending-moment time history plots. 


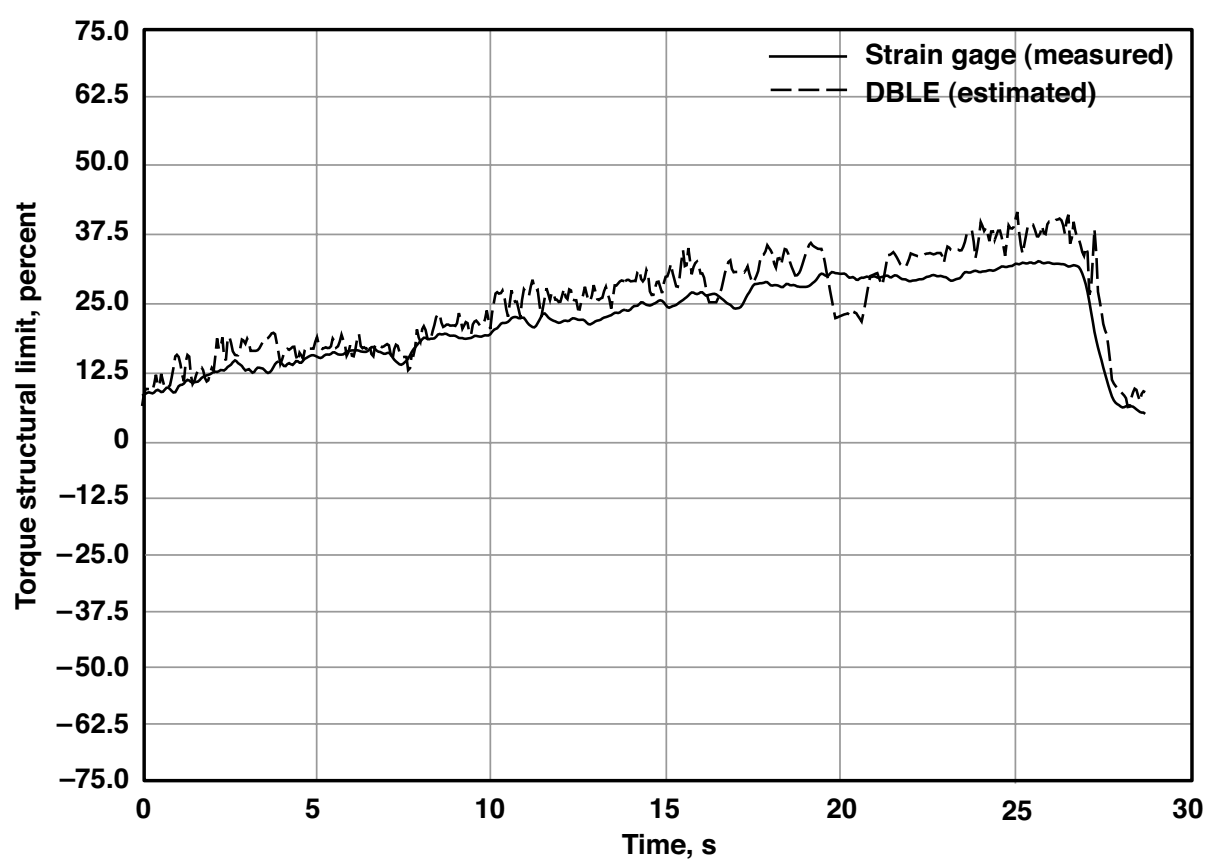

a) Wind-up turn.

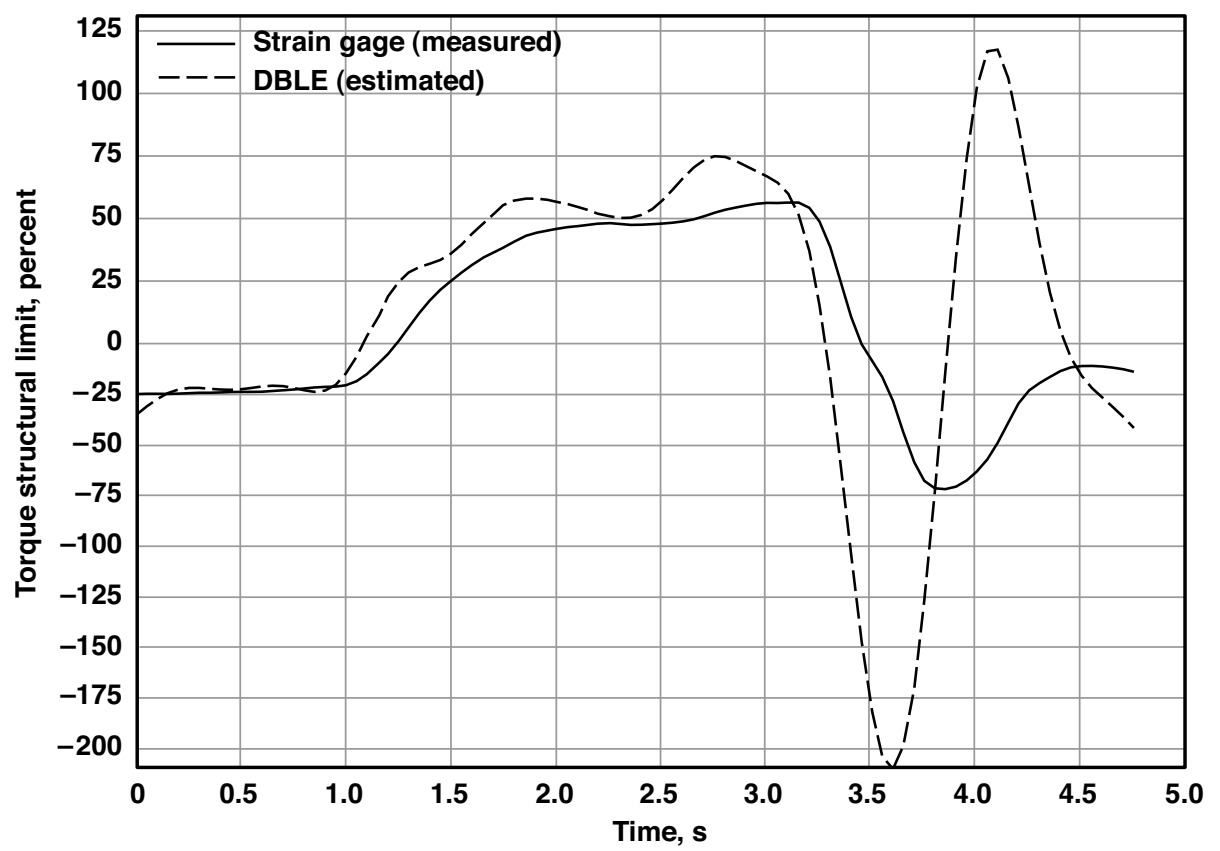

b) One-hundred-percent lateral stick roll.

Figure 11. Wing-fold torque time history plots. 
Structural hysteresis is also noted from maneuver to maneuver. Figure 12(a) shows two target 12 (see Fig. 5) deflection time history plots from right stick rolls at approximately 50 percent lateral stick. The two maneuvers were flown at the same flight condition with approximately $50 \mathrm{~s}$ of separation. The solid trace shows deflection from a right roll immediately following a left roll at 50 percent lateral stick. The dashed trace shows deflection from a right roll immediately following the abovementioned right roll. Figure 12 time history plots illustrate the nonlinear steady-state wing deflection based on maneuver history. Following the initial left roll at steady and level flight, target 12 is approximately 1.4 in., however, following the first right roll target 12 reaches steady state at approximately $1.7 \mathrm{in}$. A deflection difference of approximately $0.3 \mathrm{in}$. is noted based purely on previous maneuver loading.

Figure 12(b) shows a time history of the deflection difference between target 10 and target 12 for the two right rolls. The streamwise deflection difference is independent of the prior maneuver as both right rolls begin with approximately -0.29 in. delta. It can be concluded that the angle of twist at this span station is the same between maneuvers, however, the overall vertical deflection of the wing has changed. Figure 12(c) shows the wing-root torque time history of the two rolls. From the same delta of -0.29 in. as shown in Fig. 12(b), the WRTL is assumed to be similar from the rolls, but is substantially different.

Also noted is the deflection range difference in the two right rolls of Fig. 12(a). From the second right roll a much greater deflection range is shown. Based on this evidence, to make the deflection-based load estimation more accurate, it is proposed that the load estimation must be a function of deformation and understanding of the previous loading cycle.

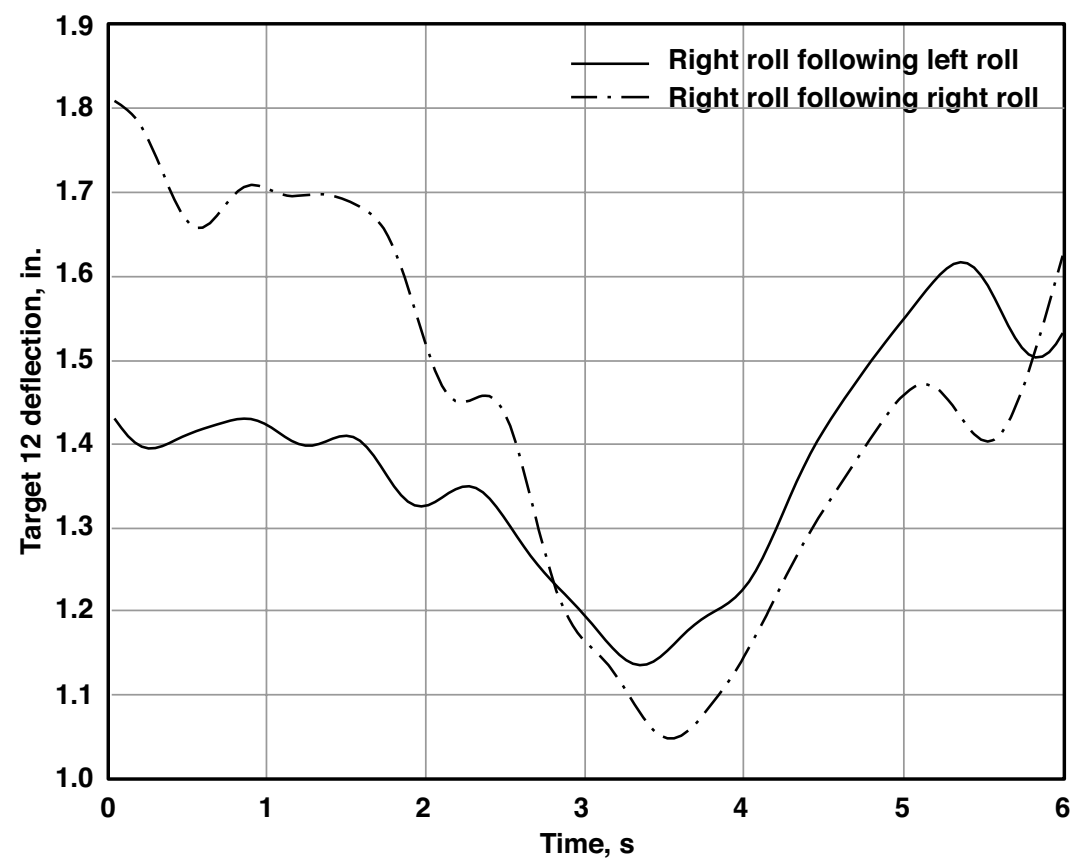

a) Target 12 deflection.

Figure 12. Back-to-back right roll time history plots. 


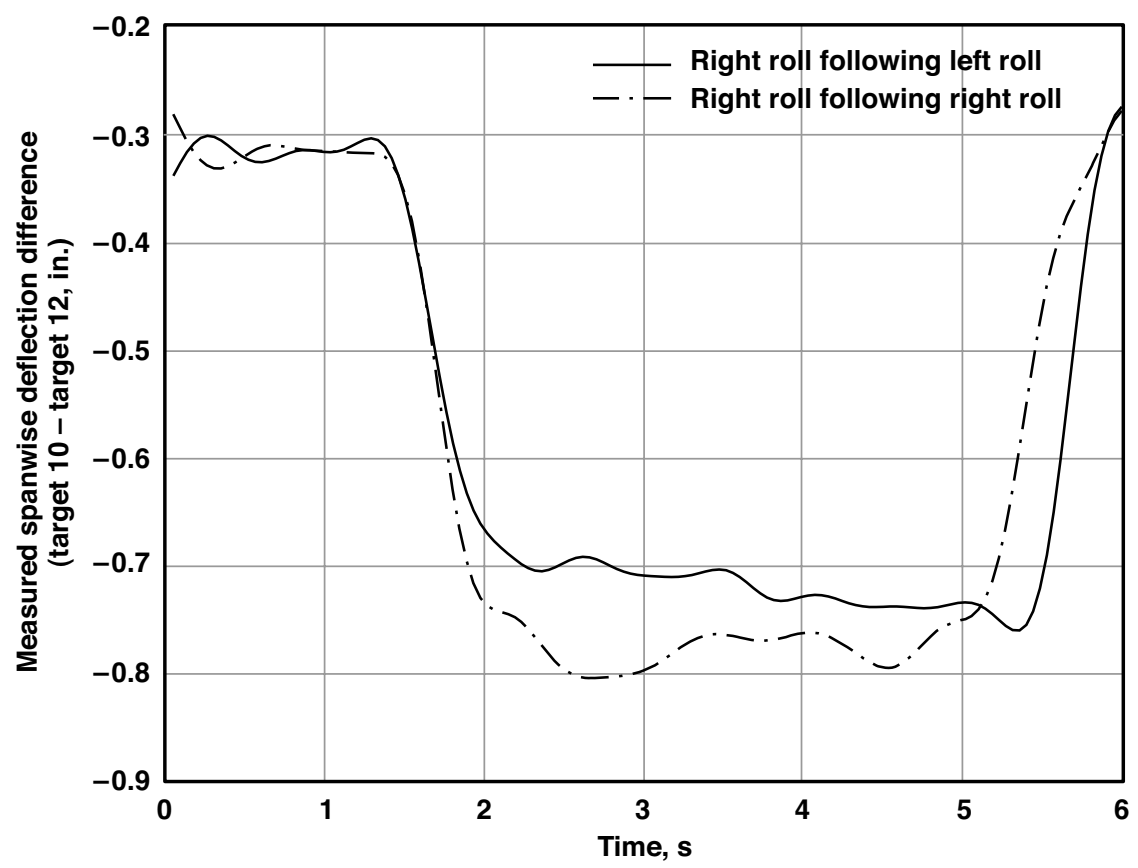

b) Deflection difference between target 10 and target 12 .

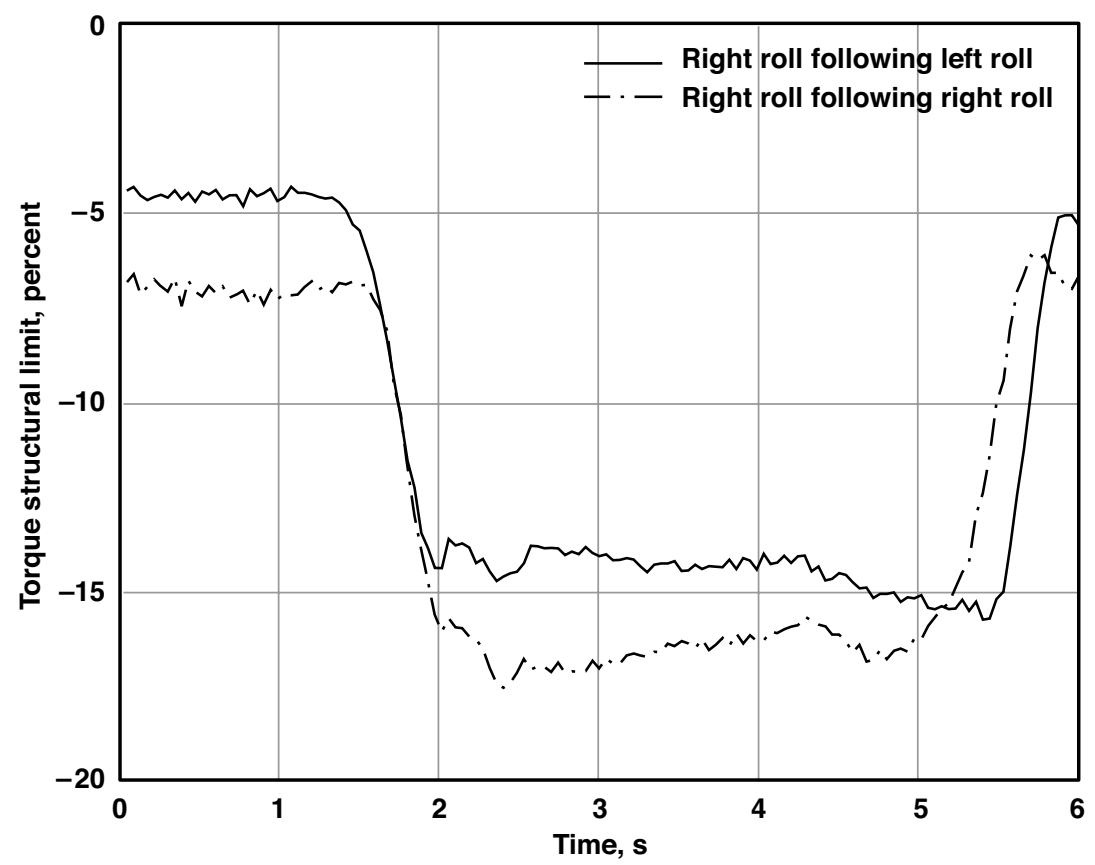

c) Wing-root torque.

Figure 12. Concluded. 
It is also important to mention the effect on the outboard wing vertical displacements because of the rotational free-play of the wing-fold hinge mechanism. Targets outboard of the fold were set to zero at ground rest. Exertion of little upward vertical force at the wingtip causes the structure outboard of the fold hinge to move with minimal wing-root or wing-fold load response. Transitions between the ground rest displacement of zero will give erroneous DBLE results because the wing is not a continuous structure. To compensate for this error, targets inboard of the fold, where the wing structure is continuous, must be used in load estimation or else only maneuvers with significant outboard deflection may be analyzed with confidence. A wind-up turn, for instance, typically provides a purely positive vertical wing deflection and high bending load.

Typically, high bending-moment loads were associated with a large structural deflection range. High torque loads, in contrast, are not always associated with large structural deflections, making the torque resolution poorer and resulting in a more noisy calculation. Because of this smaller observable deflection range caused by torque load, any future improvement in deflection measurement resolution should help torque load estimation results. Figure 13 shows a plot of the wing-root torque load during a doublet maneuver. Although the load reaches -50 percent of the WRTL structural limit, the maximum deflection of the targets used in this equation occurs at target 14, where the wingtip is deflected approximately 2.2 in. at this time.

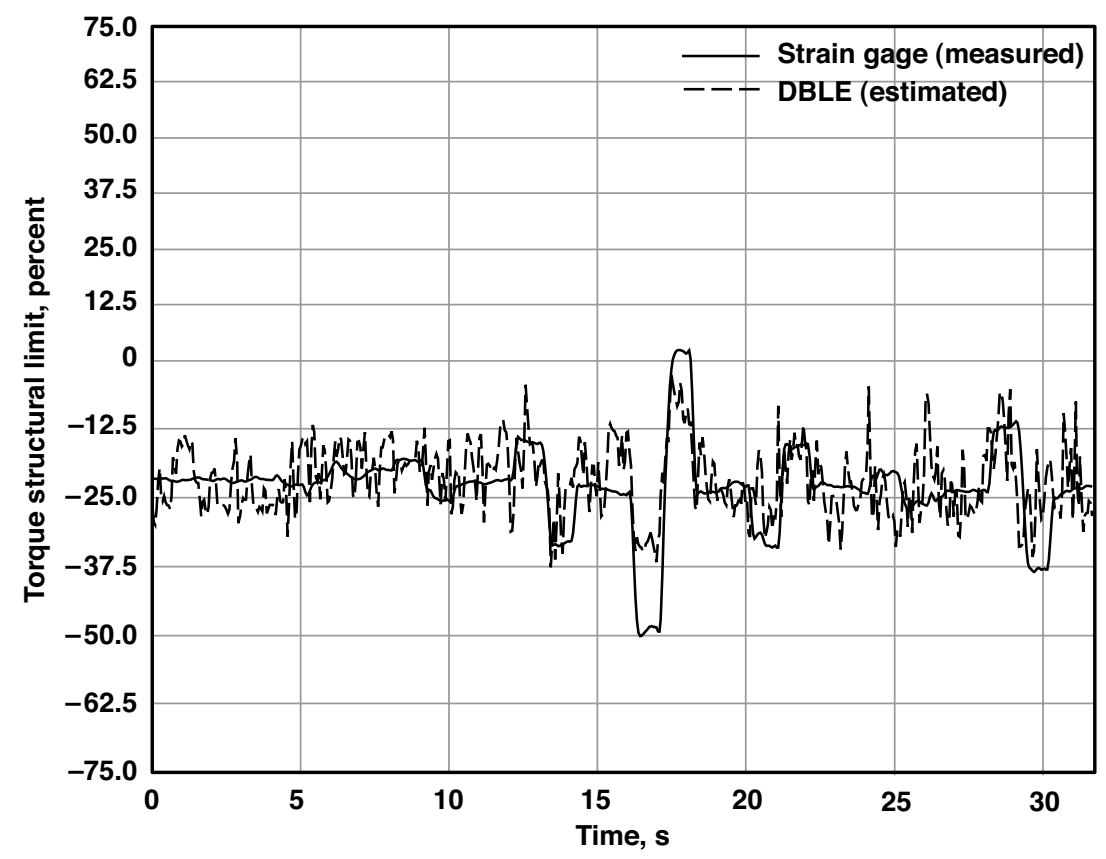

Figure 13. Wing-root torque doublet time history.

\section{Concluding Remarks}

A study was performed to explore the possibility of using the flight deflection measurement system on board the active aeroelastic wing F/A-18 aircraft to remotely measure aerodynamic loads. Although strain gages are a highly accurate and repeatable load measurement device, advantages and disadvantages to using this instrumentation exist and were briefly discussed. It is proposed that the ability to estimate loads based on component shape calibration instead of strain-gage calibration would reduce aircraft weight and test preparation time, be more accommodating to install, and eradicate strain-gage-associated issues, thus improving aircraft performance and lowering test costs.

Calibration data from ground-tests performed on the active aeroelastic wing F/A-18 aircraft were initially used to derive left wing-root and wing-fold bending moment and torque strain-gage-based load equations, but for this study were used with recorded elastic structural deflections to derive deflection-based load equations. A multiple linear regression tool was used to correlate the wing deflection at 16 different locations with measured load. Quantitative results from the deflection-based load estimation calibration showed lower root bending-moment error when compared to the traditional strain-gage method, but slightly worse fold bending-moment and torque errors. These calibration results are consistent with flight data as the two methods are comparable in bending however yield inconsistent torque results 
The main influences behind the disparities in the deflection-based load estimation torque results are structural hysteresis, wing-fold mechanical free-play, and high flight deflection measurement system resolution. Interaction between wing structural components, especially worn or loose fastener fits during flight, biases the aircraft structural response, thus the wing structural history affects the future deflection state. Therefore, to make the deflection-based load estimation method more efficient, load must be a function of deflection and the previous loading cycle. Another source of error was the wing-fold hinge free-play. Although targets outboard of the fold were initialized to zero at ground rest, slight vertical force on the wingtip deflected the structure outboard of the fold with minimal load response. Transition through zero wing displacement, as with some rolls, will not provide accurate load estimation, however loading under a purely positive wing deflection, as with wind-up turns, proved to be reasonably accurate. Typically, high bending-moment loads were associated with a large structural deflection range. High torque loads, in contrast, are not always associated with large structural deflections, making the torque resolution much worse, producing a more noisy calculation.

For these reasons, the deflection-based load estimation technique, though it produces excellent results for bending-moment loads, must be refined to produce more accurate torque load results. Future study would be required to characterize the bending-moment and torque load as a function of deformation and time because of structural hysteresis. This characterization may be accomplished through a dynamic or quasi-static deflection-based load calibration. Although the flight deflection measurement system was used here to determine deformation, comparison of real-time mathematical model deflection and photogrammetric methods would provide for a valuable future investigation.

\section{References}

${ }^{1}$ Skopinski, T.H., Aiken, W.S., and Huston, W.B., "Calibration of Strain-Gage Installations in Aircraft Structures for the Measurement of Flight Loads," NACA Report 1178, 1954.

${ }^{2}$ Pendleton, E.W., Bessette, D., Field, P.B., Miller, G.D., and Griffin, K.E., "Active Aeroelastic Wing Flight Research Program: Technical Program and Model Analytical Development," Journal of Aircraft, Vol. 37, No. 4, 2000 , p. 554.

${ }^{3}$ Jenkins, J.M., and Lemcoe, M.M., "Problems Associated with Attaching Strain Gages to Titanium Alloy Ti-6A1-4V," NASA TM X-56044, 1977.

${ }^{4}$ Liu, T., Barrows, D.A., Burner, A.W., and Rhew, R.D., "Determining Aerodynamic Loads Based on Optical Deformation Measurements," AIAA 2001-0560, 2001.

${ }^{5}$ Doyle, S.K., Liu, T. and Britcher, C.P., “An Optical Technique for Measuring Unsteady Aerodynamic Loads," presented at the 48th Annual International Instrumentation Symposium, San Diego, California, 2002.

${ }^{6}$ Dryden Flight Research Center, "Flight Loads Laboratory," [online facility description], http://www.nasa.gov/centers/dryden/research/Facilities/FLL/index.html [cited February 22, 2005].

${ }^{7}$ Lokos, W.A., Olney, C.D., Chen, T., and Crawford, N.D., "Strain Gage Loads Calibration Testing of the Active Aeroelastic Wing F/A-18 Aircraft,” NASA/TM-2002-210726, 2002.

${ }^{8}$ Jenkins, J.M., and DeAngelis, V.M., “A Summary of Numerous Strain-Gage Load Calibrations on Aircraft Wings and Tails in a Technology Format," NASA Technical Memorandum 4804, 1997.

${ }^{9}$ Lokos, W.A., and Stauf, R., "Strain-Gage Loads Calibration Parametric Study,” NASA/TM-2004-212853, 2004.

${ }^{10}$ Burner, A.W., Lokos, W.A., and Barrows, D.A., "In-flight Aeroelastic Measurement Technique Development," 48th Annual SPIE Meeting: SPIE Optical Diagnostics for Fluids, Solids, and Combustion II, San Diego, California, 2003.

${ }^{11}$ DeAngelis, V.M., and Fodale, R., "Electro-Optical Flight Deflection Measurement System," SFTE Technical Paper 22, 1987. 1981.

${ }^{12}$ DeAngelis, V.M., "In-Flight Deflection Measurement of the HiMAT Aeroelastically Tailored Wing," AIAA-81-2450,

${ }^{13}$ Lokos, W.A., "Predicted and Measured In-Flight Wing Deformations of a Forward-Swept-Wing Aircraft," Society of Flight Test Engineers $21^{\text {st }}$ Annual Symposium Proceedings, 1990, p.3.1-1.

${ }^{14}$ Powers, S.G., Webb, L.D., Friend, E.L., and Lokos, W.A., "Flight Test Results From a Supercritical Mission Adaptive Wing With Smooth Variable Camber," NASA Technical Memorandum 4415, 1992.

${ }^{15}$ Bonnema, K.L., and Lokos, W.A., “AFTI/F-111 Mission Adaptive Wing Flight Test Instrumentation Overview,” Paper No. 89-0084, Proceedings of the $35^{\text {th }}$ International Instrumentation Symposium, Instrument Society of America, North Carolina, 1989 , p. 809.

${ }^{16}$ Lokos, W.A., Bahm, C.M., and Heinle, R.A., "Determination of Stores Pointing Error Due to Wing Flexibility Under Flight Load,"NASA Technical Memorandum 4646, 1995.

${ }^{17}$ Lizotte, A.M., and Allen, M.J., "Twist Model Development and Results from the Active Aeroelastic Wing F/A-18 Aircraft,"NASA/TM-2005-212861, 2005.

${ }^{18}$ Lokos, W.A., Olney, C.D., Crawford, N.D., Stauf, R., and Reichenbach, E.Y., "Wing Torsional Stiffness Tests of the Active Aeroelastic Wing F/A-18 Airplane,”NASA/TM-2002-210723, 2002. 